\title{
CRESCER OU SENTIR? \\ Os repertórios culturais do amor no reality-show "Casados à Primeira Vista"
}

\author{
Fernando Ampudia de Haro
}

Universidade Europeia, Lisboa, Portugal, Instituto de História Contemporânea (IHC NOVA

FCSH), Lisboa, Portugal

Resumo O objetivo do artigo é analisar os repertórios culturais sobre o amor no reality-show "Casados à Primeira Vista" (SIC). Ao nível teórico, esta análise parte de uma noção pragmática da cultura defendida por autoras como Ann Swidler ou Eva Illouz. O material empírico examinado inclui os diferentes episódios semanais do programa, onde se realizou uma análise de conteúdo temática. Os resultados mostram que existem dois repertórios genéricos sobre o amor, conceptualizado como "crescimento" ou como "sentimento". Tais repertórios estão expostos a tensões que, em última instância, acabam por gerar ambivalência cultural

Palavras-chave: sociologia da cultura, amor, televisão, comunicação.

To grow up or to feel? The cultural repertoires of love in reality-show "Married at First Sight"

Abstract The aim of this paper is to analyse the cultural repertoires about love in Portuguese reality-show "Married at the First Sight" (SIC). Theoretically, this analysis is based on a pragmatic concept of culture presented by authors as Ann Swidler and Eva Illouz. The empirical material includes the weekly episodes of this television show. This material is examined according to content analysis. Results show two generic types of cultural repertoires focused on love, conceptualized as a "feeling" or as a "growing process" of oneself. Such repertoires are submitted to a certain tension which finally produces cultural ambivalence.

Keywords: sociology of culture, love, television, communication

Grandir ou sentir ? Les répertoires culturels de l'amour dans le programme de téléréalité "Mariés au premier regard"

Résumé L'article analyse les répertoires culturels sur l'amour dans le programme de téléréalité “Mariés au premier regard", diffusé au Portugal sur la chaîne de télévision SIC. Au plan théorique, cette analyse part d'une notion pragmatique de la culture défendue par des auteures comme Ann Swidler ou Eva Illouz. Le matériel empirique examiné inclut les différents épisodes hebdomadaires du programme, afin de faire une analyse de contenu thématique. Les résultats montrent qu'il existe deux répertoires génériques sur l'amour, conceptualisés comme "croissance" ou comme "sentiment". Ces répertoires sont exposés à des tensions qui, en dernière analyse, finissent par générer une ambivalence culturelle.

Mots-clés: sociologie de la culture, amour, télévision, communication.

¿Crecer o sentir? Los repertorios culturales del amor en el reality-show “Casados a Primera Vista"

Resumen El objetivo del artículo es analizar los repertorios culturales sobre el amor en el reality-show portugués "Casados a Primera Vista" (SIC). Teóricamente, el análisis parte de una noción pragmática de cultura basada en las aportaciones de Ann Swidler y Eva Illouz. El material empírico que se examina comprende los diferentes episodios semanales del programa, a los cuales se aplica un análisis de contenido según temas. Los resultados revelan la existencia de dos repertorios genéricos sobre el amor, conceptualizado como "crecimiento" o "sentimiento". Dichos repertorios se encuentran sometidos a tensiones que, en último término, acaban por generar ambivalencia cultural.

Palabras-clave: sociología de la cultura, amor, televisión, comunicación. 


\section{Introdução}

Segundo François de la Rochefoucauld (1613-1680), escritor, filósofo e poeta, há pessoas que não se teriam apaixonado nunca se jamais tivessem ouvido falar sobre o amor (Illouz, 2009: 142). Ou, acrescentaríamos nós numa versão atualizada da mesma sentença, se não o tivessem visto na televisão. A televisão é um meio essencial para compreender as representações sociais da realidade e o conteúdo da nossa cultura e, mais especificamente, a conformação da imagem do amor nas nossas sociedades. Como tal, os programas televisivos podem ser entendidos como objetos culturais que contêm significados, símbolos, prescrições e orientações, quer a nível comportamental, quer a nível emocional. Daí deriva, precisamente, o seu interesse para as ciências sociais.

Na televisão, o amor é um tema recorrente que pode materializar-se em diferentes objetos culturais, como filmes e telenovelas. Mas também num reality-show como "Casados à Primeira Vista" (CPV), do qual se ocupa o presente artigo. Como produto televisivo, CPV exibe diferentes repertórios culturais sobre o amor enquanto emoção e fundamento do casamento. Neste programa, os participantes casam com pessoas que não conhecem previamente e que também não foram escolhidas por eles. Um grupo de peritos efetua tais escolhas com base na avaliação da sua compatibilidade psicológica. Após a cerimónia de casamento, o copo de água e a lua de mel, os novos casais devem viver juntos com o objetivo de consolidar a sua união matrimonial. Como acontece com qualquer produto de telerrealidade, os espetadores assistem a este processo ao longo de diferentes episódios diários e semanais.

Porque é que é relevante estudar um programa desta natureza? Porque se trata de um objeto que informa acerca da maneira que temos de pensar e de sentir o amor na sociedade e que permite indagar o marco cultural onde se enquadra esta emoção. É, pois, uma ferramenta hermenêutica com uma repercussão significativa entre a audiência e a opinião pública. Como assinala Eva Illouz (2003), os objetos culturais capazes de gerar controvérsias são aqueles que melhor mostram os pressupostos culturais que assumimos quando falamos no amor e das disputas em torno dele. ${ }^{1}$

O objetivo deste trabalho é analisar os repertórios culturais sobre o amor que se podem encontrar num objeto cultural como CPV. Mais especificamente, exploram-se os significados e sentidos atribuídos (a) à decisão sobre a eleição do marido ou da esposa; (b) ao amor, tanto como resultado do sentimento e do afeto, como resultado da transformação psicológica do casal, e (c) ao casamento e à performance das práticas a ele vinculadas. Uma vez estudados tais significados e sentidos,

1 Ver, como exemplo, Filipa Rosa, "Casados à Primeira Vista: Programa da SIC pode provocar confusão na cabeça dos filhos dos concorrentes", Revista Crescer, 2019, https://www.crescercontigo.pt/casados-a-primeira-vista-programa-da-sic-pode-provocar/ ; ou Inês Rocha, "Casados à Primeira Vista promove uma 'banalização do casamento', diz Igreja, Rádio Renascença, 16/11/2018, https://rr.sapo.pt/2018/11/16/pais/casados-a-primeira-vista-promove-uma-banalizacao-do-casame nto-diz-igreja/noticia/130798/ 
examinam-se as contradições que geram, isto é, como é produzida a ambivalência cultural a partir dos próprios repertórios.

A análise que se propõe enquadra-se numa aproximação pragmática ao estudo dos repertórios culturais, na sequência das propostas teóricas na sociologia da cultura de Ann Swidler (1986) e Eva Illouz (2008). Sob a ótica pragmática, a cultura é conceptualizada como uma caixa de ferramentas (tool-kit) com recursos ao dispor dos indivíduos para interpretar a realidade social. Nesse sentido, CPV ilustra narrativas sobre o amor e o casamento disponíveis para um público que deseje interpretar o sentido das emoções amorosas ou do matrimónio. Junto da sociologia da cultura como referência teórica, as ciências da comunicação também são convocadas neste artigo para determinar o estatuto epistemológico do reality-show e a sua caraterização dentro dos diferentes géneros televisivos. Graças a isto, estaremos em condições de compreender que tipo de realidade é transmitida pela telerrealidade, um ponto essencial na aproximação a CPV como objeto cultural.

O material empírico no qual este artigo se centra corresponde à primeira temporada do programa em Portugal, entre outubro e dezembro de 2018. Este material é submetido a uma análise de conteúdo de acordo com temas e componentes constitutivas a partir das diretrizes de Bardin (2011: 73-80). De acordo com isto, a primeira parte do artigo aborda a conceptualização de CPV como objeto cultural capaz de oferecer repertórios interpretativos sobre o amor e o casamento. A segunda parte, centra-se no estatuto epistemológico do programa televisivo, isto é, na sua articulação com diversos níveis de realidade mediada. A terceira parte apresenta o procedimento metodológico. A quarta parte é dedicada à análise dos repertórios culturais sobre o amor e o casamento e ao estudo da produção da ambivalência cultural. Finalmente, a última parte é reservada às conclusões.

\section{“Casados à Primeira Vista" como objeto cultural}

"Casados à Primeira Vista" pode ser visto como um objeto cultural que reflete e torna explícitos diferentes repertórios culturais sobre o amor e o casamento. Esta interpretação exige esclarecer, em primeiro lugar, o conceito de cultura que a suporta. Segundo Schudson (1989), existem duas abordagens clássicas sobre a cultura nas ciências sociais. Por um lado, a noção de cultura como sistema social ou ideologia que, impositivamente, determina a orientação e a finalidade da ação humana. Esta perspetiva é afim aos postulados marxistas e estrutural-funcionalistas. Por outro lado, uma noção de cultura como recurso interpretativo da realidade, e que funciona como um conjunto de símbolos e de ideias dos quais se servem as pessoas para executar as suas ações em função das situações e do contexto em que vivem.

Esta segunda perspetiva, associada a uma visão pragmática da cultura, é a que adotamos neste trabalho. Sendo assim, CPV recolhe diversos repertórios, isto é, recursos interpretativos, sobre o amor, as relações, o casamento e as emoções que os participantes mobilizam segundo as conjunturas que se apresentam. Devemos a Ann Swidler (1986) o mais completo desenvolvimento da visão pragmática da 
cultura. Segundo a autora, a cultura oferece repertórios como símbolos, rituais e esquemas do mundo dos quais a pessoa se vale para se orientar numa dada situação ou para resolver problemas práticos. Neste caso, por exemplo, os que derivariam das relações afetivas ou do casamento. Tais repertórios não determinam a ação dos atores sociais mas, sim, oferecem pautas para agir. Essas pautas não são infinitas nem a sua utilização responde necessariamente a algum tipo de cálculo utilitário-racional por parte dos indivíduos. Swidler diz-nos que existem uma série de ações estruturalmente organizadas, ou seja, soluções habituais que as pessoas usam recorrentemente para lidar com situações e contextos diversos. Esse uso recorrente explica o efeito da cultura ao longo do tempo.

Se aplicarmos esta ideia ao tema do amor, veremos que existem fórmulas explicativas e interpretativas culturalmente estabelecidas sobre, por exemplo, as fases típicas de um relacionamento, as práticas associadas e os estados emocionais expectáveis para cada uma delas. Quem utiliza esses repertórios possui a capacidade para o fazer na medida em que os aprendeu e interiorizou através da socialização. Ao mesmo tempo, continua a treiná-los, praticá-los e aperfeiçoá-los sempre que se depara com situações onde é requerida a sua aplicação. Neste sentido, CPV expõe os recursos culturais usados pelos seus protagonistas, mas simultaneamente, pode constituir um recurso ao qual acedem os sujeitos como espetadores para interpretar o amor e o casamento.

A linha interpretativa pragmática aberta por Swidler é continuada por Eva Illouz nos seus estudos sobre o amor na cultura contemporânea $(2009,2012)$. Para a autora, objetos culturais como os reality-shows, os filmes, os romances, as revistas femininas ou as músicas são artefactos interpretativos mediante os quais os indivíduos captam o sentido do mundo. Fornecem símbolos, metáforas, histórias, imagens, conceitos e uma síntese de conhecimento leigo e especializado, útil para organizar e interpretar a conduta e as emoções (Illouz, 2008). Como tal, CPV é relevante como recurso cultural acerca dos significados do amor, mas também como instrumento apto para lidar discursivamente com a instabilidade, a incerteza e a fragmentação das biografias contemporâneas que perturbam a relação amorosa. Em consequência, sob a perspetiva pragmática, um objeto cultural como CPV, adscrito à telerrealidade, não é conceptualizado como uma prova de falsa consciência, como imposição ideológica, como máscara dos interesses dominantes ou como um regime de controlo da conduta. Pelo contrário, é algo que nos permite atribuir sentido e significado ao que vemos, fazemos, sentimos e pensamos, neste caso, no domínio das relações afetivas.

A noção da cultura defendida por Swidler e Illouz é especialmente apropriada para o estudo dos objetos culturais e da sua relação com a conduta e as emoções. Contudo, não é este o enfoque dominante dentro da sociologia na sua aproximação ao universo das emoções. Têm sido mais habituais as perspetivas que incidem nos vínculos entre o sentimento e a transformação estrutural da sociedade (García Andrade, 2015; Felmlee e Sprecher, 2006). Exemplo disto são Giddens, Beck e Beck-Gernsheim ou Baumann. Para Giddens (1997), a modernidade tardia define umas condições sociais propícias para um tipo de amor confluente fundado na igualdade das partes e cujo compromisso se baseia exclusivamente na vontade dos 
indivíduos. No caso de Ulrich Beck e Elisabeth Beck-Gernsheim (2001), a sociedade contemporânea gera uma situação estrutural onde existem instituições que funcionam ainda como na primeira Modernidade - o emprego, por exemplo - enquanto outras, como o matrimónio, operam segundo a lógica da segunda Modernidade. Isso implica que, na vida a dois, sejam tidos em conta fatores como a igualdade dos géneros, a libertação sexual ou a autorrealização identitária. Afinal, no terreno do amor, os indivíduos acabam por viver as contradições estruturais como se estas fossem problemas individuais. Pela sua parte, Bauman (2006) salienta a fragilidade do vínculo amoroso num mundo líquido e contingente onde não existe qualquer obrigatoriedade no vínculo afetivo, ameaçado sempre pela possibilidade de viver novas e melhores experiências. Apesar do domínio desta visão focada nas estruturas sociais que influenciam o amor, a proposta culturalista pragmática que protagonizam Swidler e Illouz tem produzido leituras ricas e complexas sobre as possibilidades que a cultura oferece para outorgarmos um sentido e um significado às nossas emoções. Neste campo, é preciso salientar o trabalho pioneiro de Bellah, Madsen, Sullivan, Swidler e Tipton (1985) na exploração das afinidades da cultura individualista dos Estados Unidos de América (EUA) com visões do amor inspiradas pela religião e pela psicoterapia. A própria Swidler (2001) dedicou um notável trabalho às conceções do amor nos EUA, oscilantes entre versões românticas e prosaicas segundo as condições que as pessoas tivessem de gerir nas suas experiências emocionais. Por último, cabe referir a obra de Hochschild (2003) sobre o desenvolvimento de estratégias e estilos de gestão emocional como forma de compensar a incerteza estrutural que preside ao amor na sociedade contemporânea.

Em suma e se, como acontece neste artigo, o objetivo é conhecer e analisar repertórios culturais sobre o amor, parece adequado que a visão adotada esteja mais próxima do marco teórico culturalista pragmático que aborda a relação entre significado, sentido e objetos culturais. Só dessa forma, um programa como CPV adquire um estatuto relevante como fonte para explorar tais repertórios.

\section{A realidade da telerrealidade: definição, classificação e estatuto epistemológico do reality-show}

De acordo com Misha Kavka (2012: 5), um programa de telerrealidade é um espetáculo televisivo sem guião e com atores não profissionais observados por câmaras numa situação e num ambiente predeterminados. Como espetáculo, integra elementos procedentes do mundo do documentário, da telenovela, do jogo e do talk-show. Taxonomicamente, enquadra-se no subgénero do docudrama, caraterizado pela combinação de fórmulas associadas quer à informação, quer à ficção (Gordillo e Ramírez Alvarado, 2009). Esta hibridação entre o real e o ficcional traz consigo uma renegociação constante entre o referente e a representação, assim como um questionamento de dicotomias clássicas dentro da cultura ocidental: privado e público, celebridade e anonimato, autenticidade e interpretação ou verdadeiro e falso são algumas das categorias desafiadas (García Martínez, 2009). 
Em termos de evolução histórica, o programa identificado como pioneiro neste campo é "An American Family" (1973), que mostrava o dia a dia da família Loud com uma lógica próxima do documentário (Montemurro, 2008). Este é ainda um produto isolado até à concretização das sucessivas fases no desenvolvimento da telerrealidade. Segundo Kavka (2012), existem três grandes etapas nesse desenvolvimento. A primeira inicia-se a meados dos anos 1980 da mão de programas sobre crime e atividade policial, cenas domésticas e familiares de tom cómico ou situações quotidianas imprevistas. Grande parte do material exibido é registado pelos próprios espetadores graças à generalização da vídeo-câmara pessoal. A segunda tem lugar nos anos 1990 com a proliferação de formatos que misturam vigilância e competição. Neste caso, o produto paradigmático é "Big Brother" que, com diferentes variações, chega até hoje. À componente documental junta-se a vertente competitiva, facilmente adaptável à venda internacional de um formato extremamente apelativo para anunciantes, dado o elevado nível de audiências. A terceira, que arranca na década de 2000 e na qual ainda estaríamos imersos, corresponde à consolidação dos formatos de desafio e transformação. A telerrealidade sofre uma regressão dos seus elementos documentais (García Martínez, 2009) face ao avanço das componentes lúdicas, conversacionais e dramáticas. São programas que visam a intervenção na vida das pessoas oferecendo uma oportunidade de autorrealização a nível físico e psicológico.

CPV enquadra-se neste último grupo. É um tipo de reality-show que adota a modalidade de coaching-show (Gordillo e Ramírez Alvarado, 2009; Costa Sánchez, 2010) e que, como tal, permite ao espetador assistir ao processo de transformação dos participantes. Estes aceitam a intervenção de peritos no seu quotidiano e na sua intimidade para corrigir ou eliminar algum tipo de situação ou caraterística física ou mental que é vista como sendo negativa ou indesejável. Para isso, a câmara penetra na esfera pessoal gerando narrativas espetaculares e dramatizadas de mudança individual. No caso de CPV, a transformação envolve a passagem à condição de pessoa casada, assim como a aquisição das disposições comportamentais e emocionais que permitam um relacionamento bem-sucedido. Contudo, CPV não é um caso isolado de coaching-show na televisão portuguesa. Em "Super-Nanny" (SIC, 2018 $)^{2}$ uma psicóloga ajudava os pais a ultrapassar as dificuldades que se colocavam na educação dos seus filhos. "Fear Factor" (TVI, 2004) ensinava os participantes a confrontar os seus medos com a colaboração de vários psicólogos. Os donos de cães encontravam em "O Encantador de Cães" (SIC, 2011) um recurso para adestrar os seus animais de estimação. Em "Operação Trunfo" (RTP1, 2003) ou "The Voice Portugal" (RTP1, 2011), professores e músicos profissionais ensinam e avaliam os candidatos a artistas. “Querido, Mudei a Casa” (TVI, 2014) mostra como dar uma nova orientação à vida refazendo a residência pessoal com a ajuda de $d e-$ signers de interiores e decoradores. E, por último, "Peso Pesado" (SIC, 2011) mostra o processo de regeneração física de pessoas com um peso corporal elevado. Em

2 Na enumeração dos diferentes exemplos, é indicado sempre o ano original do lançamento e a cadeia televisiva. 
suma, estes exemplos enquadram-se na categoria de coaching-show, visando algum tipo de transformação individual mediada pela figura do perito. Especificamente, à volta da temática do amor e do casamento, embora no âmbito internacional e de acordo com Kavka (2005), podemos referir "The Bachelor" (ABC, 2002), "Joe Millionnarie" (Fox, 2003), "Perfect Match" (Channel 4, 2001), "Who Wants to Marry a Multimillionnarie" (Fox, 2001, adaptado pela TVI como "Pedro, o Milionário") e "Who Wants to Marry a Prince" (Fox, 2002).

O aspeto mais complexo e intelectualmente desafiante é, sem dúvida, determinar que tipo de realidade oferece a telerrealidade. Se assumirmos que CPV é um objeto cultural articulado segundo diferentes repertórios culturais acerca do amor, é pertinente conhecer quão reais são esses repertórios ou, por outras palavras, qual é o estatuto epistemológico de programas televisivos que se apresentam a si próprios como um reflexo da vida real. Perante isso, devemos adotar alguma cautela: 0 que está a ser emitido não é estritamente factual. Existe um trabalho de edição, linhas argumentais e contextuais onde os participantes são intencionalmente inseridos. Estes vivem situações manufaturadas pelos produtores, que também podem construir identidades específicas dos participantes salientando ou ocultando as suas caraterísticas (Montemurro, 2008). É, pois, uma realidade mediada onde o sentido do real é gerado, de acordo com Kavka (2005), pela transmissão ao vivo ou pela capacidade para elaborar uma não mediação construída na fase de produçãoe pós-produção. Estamos perante um estatuto epistemológico que combina duas epistemes (Hill, 2014; García Martínez, 2009): a veracidade do mundo quotidiano e a veracidade das indústrias culturais. Dá-se uma constante entrada e saída do domínio da realidade e da realidade mediada. Afinal, a promessa de se assistir à realidade ao vivo é atraente para a audiência, ao tempo que esta se debate com o dilema constante de saber que é ou não real (Hall, 2009; Escoffery, 2006). Esta realidade mediada, produto de uma não mediação construída, conta também com a reflexividade do público e dos próprios participantes nos programas. Relativamente ao público, hoje é preciso estarmos conscientes da experiência e da aprendizagem acumuladas durante quase 40 anos de telerrealidade. Neste sentido, como aponta García Martínez (2009: 246), o espetador pós-moderno é um indivíduo socializado na suspeita da televisão, um indivíduo relativamente educado na distinção entre o "real" da "realidade" e o "real" do reality-show. De facto, o público parece assinar uma espécie de contrato personalizado de descrença no conteúdo televisivo (Jones, 2003; Montemurro, 2008). Isto é, suspende-se temporariamente a conviç̧ão de estar perante uma realidade construída para adotar a lógica da realidade proposta pela televisão. Este nível de reflexividade do público faz com que se procure, não tanto a realidade, como a autenticidade na encenação dos participantes do programa. Isso significa outorgar a atenção e o valor aos momentos em que os intervenientes conseguem mostrar o seu verdadeiro Eu apesar das câmaras ou, dito de um outro modo, quando os participantes exibem coerência entre o seu comportamento e a fidelidade a esse Eu (Biressi e Nunn, 2005). Convém não esquecer que também os participantes acumulam experiência em programas de telerrealidade: já foram espetadores, sabem que estão na televisão e, por isso, a sua intimidade emerge mediada (Kavka, 2005: 97). Em prol da autenticidade, deverão fazer aquilo que 
sentem estando conscientes que nem as câmaras nem os microfones irão desaparecer. E "fazer aquilo que sentem" envolve a encenação sentimental capaz de gerar, por um lado, a perceção no espetador de que o sentimento é real e, por outro lado, a disposição no participante de que aquilo que se sente não está encenado.

Em geral, a manufaturação da realidade mediada segundo uma não mediação construída torna o estatuto epistemológico da telerrealidade necessariamente ambíguo. Nele ficam incorporadas a intencionalidade dos produtores e a reflexividade dos públicos e dos participantes, numa dinâmica constante de interdependência. É, pois, uma realidade muito particular a que suporta os repertórios culturais do amor que se estuda neste artigo.

\section{Considerações metodológicas}

Este artigo procura estudar os repertórios culturais apresentados no objeto cultural $\mathrm{CPV}$. Como objeto cultural, condensa e codifica significados e visões que circulam na nossa sociedade. É, pois, um objeto culturalmente enquadrado, um objeto que refere e reflete imagens acerca da realidade, esquemas explicativos e padrões de expressão e de ação. Como produto televisivo e com a pretensão de garantir uma conexão relevante com o público, apresenta-se depurado de significados culturalmente irrelevantes. Nesse sentido, como afirma Illouz, pode ser olhado como uma compilação abreviada das inquietações e das imagens sobre o amor presentes na nossa sociedade (Illouz, 2009: 39). Se, por um lado, podemos afirmar que, como objeto cultural inserido no meio televisivo, é uma janela que permite contemplar o mundo, por outro lado, é preciso reconhecer que também constrói esse mundo com as suas representações simplificadas e seletivas da realidade (Casetti e Di Chio, 1999).

O material empírico analisado corresponde à primeira edição do programa: 12 episódios semanais emitidos entre 21 de outubro e 31 de dezembro de 2018 e um episódio especial - intitulado "O Fenómeno" - emitido a 6 de janeiro de 2019. Os episódios semanais, emitidos aos domingos, são uma síntese dos episódios diários - 40 no total, entre 22 de outubro e 28 de dezembro de 2018 - aos quais são acrescentados os momentos de avaliação por parte dos peritos e a decisão de sair ou permanecer no programa por parte dos participantes. Embora já tenha sido emitida uma segunda edição do programa - entre 13 de outubro e 21 de dezembro de 2019 - a opção pela primeira prende-se com diferentes razões. Em primeiro lugar, a novidade do formato na televisão portuguesa gerou expetação na opinião pública, se atendermos aos significativos dados das suas audiências. ${ }^{3}$ Em segundo lugar, a estrutura do programa não sofreu qualquer alteração relativamente à primeira edição e, nesse sentido, não existem motivos substanciais que a distingam ou a tornem um alvo de atenção preferencial. E, em terceiro lugar, na segunda edição já está presente de uma forma mais evidente a reflexividade dos participantes, que tiveram

3 Por exemplo, "Casados à Primeira Vista é fenómeno de audiências", SIC, 29/11/2018, https://sic.pt/Programas/casados-a-primeira-vista/2018-11-29-Casados-a-Primeira-Vista-e-fenomeno-de-audiencias 
contacto com a primeira edição como potenciais espetadores. Essa reflexividade acrescenta uma camada de complexidade à análise, da qual resolvemos prescindir deliberadamente, com o intuito de aceder aos repertórios culturais com uma menor carga de representação.

Este material é explorado segundo o modelo de análise temática proposto por Bardin (2011). São identificados itens de significação numa unidade de codificação que, neste caso, equivalem às frases pronunciadas pelos participantes - casais e especialistas - durante as suas intervenções. Foi realizada uma pré-visualização do programa com o objetivo de adquirir alguma familiaridade com a informação e identificar os conteúdos relevantes para esta pesquisa. Neste primeiro momento, privilegiou-se uma aproximação dedutiva guiada por considerações teóricas referentes a repertórios culturais sobre o amor. Deste modo, foi possível observar que a experiência emocional e cognitiva dos participantes é articulada segundo três eixos temáticos. O primeiro prende-se com a questão da escolha, o segundo com a conceptualização do amor, e o terceiro com o funcionamento e a prática do casamento. Como tal, a identificação destes eixos corresponde a uma aproximação indutiva, uma vez que emergem do próprio conteúdo do programa. Cada um dos eixos temáticos apresenta componentes que o constituem como tema relevante. No caso da escolha, as componentes são os critérios e os agentes da decisão. Para o eixo da conceptualização do amor, as componentes são a caraterização e as ideias acerca desta emoção. Finalmente, para o eixo do casamento, as componentes constitutivas referem-se às atividades e aos requisitos relacionados com a instituição matrimonial. Associados a estas componentes, utilizamos excertos das intervenções literais dos participantes com uma finalidade ilustrativa. Tais excertos são acompanhados com a identificação do participante e o número do episódio onde podem ser localizadas as suas palavras sob a designação "Ep. número".

A análise procura identificar as relações lógicas existentes entre as componentes de cada tema, explorando os graus de coerência e incoerência. Assumindo que os repertórios culturais nunca são homogéneos, esses graus determinam, em última instância, o nível de ambivalência cultural que produz cada repertório. A apresentação dos resultados segue uma fórmula descritivo-narrativa sustentada pela interpretação dos discursos dos participantes e apoiada nos excertos literais das suas intervenções.

Como aponta Bardin (2011: 80), a análise temática exige um relativo "vaivém" entre a teoria e a técnica, ou entre a dedução e a indução. Por esse motivo, e aplicando uma recomendável prudência metodológica e epistemológica, é preciso reconhecer que o nosso objeto - os repertórios culturais - e o seu suporte material - os discursos dos participantes num programa de telerrealidade - podem ser abordados sob outro ângulo, produzindo assim leituras alternativas.

\section{“Casados à Primeira Vista" e os seus repertórios culturais}

Antes de entrar propriamente na análise, é necessário oferecer uma descrição mais ampla do funcionamento do programa assim como dos participantes. Como já foi 
mencionado, os participantes casam legalmente com um outro participante que não conhecem. Uma equipa de quatro especialistas, mediante testes e exames, determina quem é o parceiro adequado para cada pessoa. $O$ futuro casal vê-se pela primeira vez na cerimónia do casamento, à qual se segue uma lua de mel e dois meses de vida em comum. Durante a convivência, o casal realiza diferentes atividades de lazer ou formativas e recebe visitas dos especialistas, de amigos, de familiares e dos restantes casais que fazem parte do programa. Estes casais são:

- Eliana (rececionista, 28 anos) e Dave (instrutor de surf, 35 anos);

- Graça (gestora de um hostel, 55 anos) e José Luís (antiquário, 56 anos);

- Ana (instrutora de fitness, 39 anos) e Hugo (motorista de reboques, 43 anos);

- Sónia (formadora, 33 anos) e João (arquiteto, 33 anos);

- Lídia (com um projeto de negócio de decoração, 44 anos) e Francisco (antiquário, 44 anos);

- Daniela (professora de ioga, 35 anos) e Daniel (empresário, 35 anos);

- Isabel (desempregada, antiga gerente na área da restauração, 42 anos) e Claúdio (técnico informático, 37 anos).

Além dos casais, as outras figuras essenciais do programa são os especialistas, referidos aqui pelo seu nome completo:

- Eduardo Torgal. Coach e perito no Eneagram para traçar o LoveMap dos candidatos.

- Fernando Mesquita. Psicólogo clínico, terapeuta cognitivo e comportamental, mestre em Sexologia.

- Cris Carvalho. Life e business coach, especialista em programação neurolinguística.

- Alexandre Machado. Mestre em Neuropsicologia clínica e especialista em avaliação do comportamento.

\section{A escolha: entre a ciência, a intuição e o ceticismo}

Como objeto cultural, CPV parte de uma autodefinição própria apresentada aos espetadores e aos participantes. É concebido como uma experiência social onde, como afirma a sua apresentadora Diana Chaves, "a ciência é colocada ao serviço do amor" (Ep. 1). O especialista Alexandre Machado reforça a autodefinição assinalando o paralelismo do programa com uma experimentação científica, uma vez que, na sua opinião, os participantes podem ser considerados uma espécie de amostra representativa dos portugueses (Ep. 1). A cientificidade seria garantida, além da presença dos especialistas, pela utilização de ferramentas objetivas na determinação da compatibilidade entre os participantes. Essa compatibilidade, expressa numa dada percentagem, é o produto da monitorização psicológica dos futuros casais, da avaliação das suas expetativas e do exame das suas caraterísticas pessoais. A partir daí, é comunicado aos participantes que irão casar: "cientificamente, tem tudo para dar certo" afirma Alexandre Machado (Ep. 1). 
Como tal, o tema da escolha emerge como conteúdo relevante, uma escolha sustentada em critérios científicos que é justificada com base na incapacidade, na falta de perícia ou no insucesso das decisões que os participantes adotaram previamente na sua vida amorosa. Expressamente, participantes como Graça, Daniela ou Ana declaram que nunca souberam escolher ou que não tiveram "jeito" para tal (Ep. 1). Eliana é quem formula mais claramente esta ideia: "As escolhas dos especialistas e dos terapeutas serão mais acertadas do que aquelas que eu fiz" (Ep. 1). O critério do participante é desacreditado mediante factos que confirmariam a necessidade de uma escolha delegada nos peritos. Os factos que referem os participantes são infidelidades, faltas de respeito, casamentos fracassados, separações, divórcios e feridas sentimentais que portam consigo. Eis as provas que demostrariam não estarem habilitados para a escolha.

A incapacidade para escolher contrasta, nos participantes, com a afirmação rotunda da sua fé e crença no amor. Isto é, a indeterminação da escolha convive com a convicção de que o amor é sempre possível. Ana expressa-o desta forma: "Acredito que existe uma pessoa para cada pessoa" (Ep. 1). Daniel também verbaliza esta ideia sob o formato do desejo: "Quero mesmo apaixonar-me outra vez" (Ep. 2). Lídia é mais um exemplo deste modo de pensar: "Eu acredito no amor verdadeiro" (Ep. 2). Por último, Francisco realiza uma declaração de interesses no mesmo sentido: "Estou aqui para encontrar o amor da minha vida" (Ep. 2). A vocação para o amor revela uma vontade e predisposição positivas para corrigir, compensar ou eliminar as condições psicológicas individuais que estão por detrás da sua incapacidade para a escolha: carências afetivas, imaturidade e insegurança ou, por outras palavras, lacunas do foro psicológico pessoal.

Contudo, a vocação para o amor e a delegação da escolha exprimem tensões que se concretizam como dúvidas ou ceticismo acerca da cientificidade do critério dos especialistas. Sónia, por exemplo, declara que nunca teria escolhido o João, porque desde a cerimónia de casamento, está consciente de que não se identifica com ele. Na cerimónia de compromisso do episódio 3 manifesta abertamente a sua divergência com o parecer dos especialistas: "Não tenho sentimento pelo João e não posso ser condenada por isso." A sua linguagem remete para uma conceptualização da escolha com metáforas que destacam a componente espontânea, imprevista e até avessa à racionalização: “Eu acredito na química." Face a isto, ergue-se a linguagem da ciência nas palavras do especialista Alexandre Machado: "E que é a química? Não existe a química; não há cá uma troca por osmose [...] Existem padrões socioculturais nos que a Sónia acredita e que tenta rever na outra pessoa. Isso é o que existe." (Ep. 11)

Em suma, os especialistas, cientificamente legitimados, representam um tipo de escolha objetiva que se justifica pela incapacidade dos participantes para escolher, tal como provam os repetidos insucessos do seu percurso amoroso. Ao mesmo tempo, existem focos de tensão quando a escolha é conceptualizada a partir da espontaneidade experienciada como impulso, relacionada, por sua vez, com a vocação para o amor. Uma vez que essa vocação existe nos participantes, estes nunca acabam por renunciar a escolher. Tal vocação habilita-os para a escolha, apesar do discurso do especialista restringir essa possibilidade. 
O tema do amor estrutura-se a partir de dois tipos de vocabulário: o do crescimento e o do sentimento. O amor como crescimento é construído mediante as ferramentas técnicas e conceptuais fornecidas pelos especialistas, isto é, desenvolvendo a disposição psicológica correta para construir um relacionamento. Neste ponto, o psicólogo Fernando Mesquita é claro quando usa a seguinte metáfora: "Nós damos a semente, e eles têm de regar." (Ep. 3) Aos especialistas corresponde determinar a compatibilidade entre os participantes e a estes, como assinala Alexandre Machado, "cabe-lhes a paixão" (Ep. 4). O amor como crescimento pessoal constitui um processo de aprendizagem onde terão de ser desenvolvidas capacidades de autoanálise, comunicação e gestão emocional. Será preciso que o casal tenha em conta que cada membro precisa de um tempo e de um espaço para refletir e cultivar o Eu. Só com uma individualidade sólida pode a pessoa manter uma vida afetiva frutuosa. Como aponta Alexandre Machado, "numa relação há três entidades: Hugo, Ana e vocês, e é preciso dedicar tempo às três" (Ep. 3).

As cerimónias de compromisso representam o momento de avaliação do relacionamento. É esse o lugar onde são atualizadas as vontades de permanecer no casamento a partir de um exercício de introspeção pessoal. O amor edifica-se com base na disposição psíquica apropriada que o participante conhece e desenvolve graças à orientação científica dos especialistas. Mas o crescimento pessoal não explica tudo e, nesse ponto, a metáfora da semente deixa espaço para outras contribuições que não têm a sua origem no conhecimento dos peritos. Estes afirmam que qualquer participante que acreditasse que "a ciência iria resolver os seus problemas" está enganado (Ep.9). Deste modo, emerge o segundo vocabulário relativo ao tema do amor, isto é, a sua visão como sentimento.

Já vimos que os participantes reconhecem a sua vocação para o amor quando foi abordada a questão da escolha. Tal vocação, como ideia, não faz parte do vocabulário do crescimento, e sim da intangibilidade do sentimento. Esta linguagem, afim à espontaneidade dos afetos, gera tensões com a visão do amor como crescimento. E essa tensão concretiza-se na dificuldade para desenvolver uns afetos que se desejam e pretendem espontâneos. Eliana concretiza essa tensão com as seguintes palavras: "Por mais ajuda e ciência que haja, não existe um botão que nós cheguemos aqui... um interruptor, que diga 'vamos a apaixonar-nos'. Estou com esperança de sentir." (Ep. 8) O sentimento é reconhecido como algo valioso, na medida em que não seja manufaturado ou induzido. Há, pois, um ponto que o trabalho introspetivo e o autoconhecimento associados ao crescimento não podem ultrapassar. Daniel ilustra-o assim: "Eu adorava apaixonar-me pela Daniela, mas não consigo dar mais ao nível dos sentimentos." (Ep. 7) E Daniela, a sua companheira, expressa-se de forma similar: "Aqueles sentimentos mais fortes acabaram por não surgir." (Ep. 7)

CPV oferece dois repertórios diferentes para falar sobre o amor, e os participantes optam por cada um deles segundo o contexto e a potencialidade explicativa que oferecem para as diferentes situações. Mas isso não implica que os dois repertórios convivam pacificamente. De novo, Daniel e Daniela são a melhor prova 
da tensão entre o crescimento e o sentimento no amor. Na cerimónia de compromisso do episódio 7, Daniel declara que viver com a Daniela o "ajuda a crescer": "Mesmo que não consiga uma relação amorosa com a Daniela eu quero continuar a aprender." Nesta narrativa de aprendizagem e aperfeiçoamento individual, a vida no casamento é conceptualizada como uma experiência formativa. Mas Daniela não subscreve essa opinião, advertindo o Daniel do enviesamento utilitário do seu modo de pensar: "Já me descartaste e agora usas-me para treinar, para quando saíres daqui."

O amor como sentimento contém uma promessa de transformação. Quando os participantes, ao falar sobre a escolha, mobilizavam a ideia da vocação do amor, apontavam nesta direção. E, assim, Daniel afirma: “quero caminhar com alguém ao meu lado" (Ep. 2). Eliana insiste no mesmo sentido e assegura que, com o amor, espera atingir a "felicidade, começar de zero". Como tal, o amor como sentimento, como acontece com a noção de crescimento, também possui um potencial de mudança. Contudo, não será esse o léxico dominante dos participantes quando avaliam a passagem pelo programa. Concordam com a existência de uma transformação pessoal operada pela experiência do crescimento, mas não do sentimento que, como relembrava Daniela, acaba por não surgir nos casais. Estes admitem que cresceram, que houve um desenvolvimento psicológico, que melhoraram as suas competências comunicacionais, a sua gestão emocional e a sua capacidade para compreender a realidade. Tal discurso é dominante nas cerimónias de compromisso dos episódios 9 e 10 e a pivô Diana Chaves confirma o diagnóstico: “Nenhum de vocês é o mesmo que chegou aqui há uns meses." (Ep. 10)

\section{A performance do casamento}

Como vimos até agora, os participantes usam diferentes recursos para dar sentido às suas experiências sobre a escolha e o amor. Junto a estes, também existem recursos para outorgar um sentido ao casamento. Trata-se de um sentido dual onde, como veremos, encenação e autenticidade são combinadas na performance do matrimónio segundo o contexto e as situações preparadas pelos produtores do programa. Sob esta perspetiva, estar casado significa performar o casamento, isto é, executar ações na prática que se encontram numa situação de comparação mental com um modelo original ou potencial da própria ação (García Martínez, 2009: 244).

Um momento representativo dessa performance é a cerimónia de casamento. Os contraentes ilustram as emoções prototípicas de um dia transcendente - impaciência, nervos, receio de não agradar ao seu par... - os gestos - mãos dadas, beijos, amostras de carinho e de cumplicidade - e as condutas rituais - beber com os braços entrelaçados, corte conjunto do bolo dos noivos, apresentação do marido ou da mulher à família, troca de fotografias e de presentes. A lua de mel também não foge a este padrão, com cenas recorrentes de jantares românticos, passeios à beira-mar ou momentos de revelação sentimental em locais exóticos. Esta performance do casamento parece não gerar tensões, muito embora existam outras que, sim, provocam contradições. 
João, por exemplo, pede ajuda telefónica ao especialista Alexandre Machado face às dificuldades de convivência que está a ter com a Sónia durante a lua de mel, quando ela se recusa a partilhar atividades e espaços com ele. $\mathrm{O}$ especialista responde: "Ninguém tem a obrigação de representar o papel de esposa. Não sei se o João percebeu isso logo no início." (Ep. 3) Está a ser pedido, pois, um compromisso de descrença com o seu estatuto de casado. Essa descrença exige que assuma a artificialidade do casamento. Os produtores inverteram a lógica convencional e, por isso, João deve progredir, como lhe pede o especialista, desde o casamento até à emoção romântica do amor. Mais evidentes ainda são os casos de Francisco e de Hugo que, mediante uma interpretação literal do seu estatuto de casados, pretendem manter relações sexuais com as suas esposas, Ana e Lídia, como um hipotético direito associado à sua condição de maridos, um direito que elas não reconhecem e ao qual não se submetem. Neste sentido, Hugo afirma o seguinte: “Não é por ser casados que temos de ser casados. Eu penso assim, mas a Ana não pensa assim." (Ep. 4) Ana aponta que Hugo "levou demasiado à letra isto de estar casado" (Ep. 4) até formular explicitamente a sua rejeição: "Eu sou casada contigo, mas não sou a tua mulher." (Ep. 7)

Para o discurso dos especialistas, o crescimento pessoal e a correta disposição psicológica para o amor requerem um afastamento da condição legal do matrimónio, ou seja, exigem um nível de reflexividade que permita ao participante perceber a componente performativa do estatuto legal. Por outras palavras, perceber que é um casamento sem amor como sentimento cuja finalidade é ser um ponto de partida para atingir o próprio sentimento. Fernando Mesquita, especialista que exerce como psicólogo, formula assim este princípio: “Apesar de no início ter sido diferente das relações que nós vemos no dia a dia, é uma relação como qualquer outra e há que haver investimento dos parceiros para que a relação evolua." (Ep. 9)

\section{“Casados à primeira vista" e a ambivalência cultural do amor}

A autodefinição de CPV faz dele um programa com uma dupla intencionalidade pedagógica. Primeiro, pretende o desenvolvimento de um tipo de afetividade e de regulação psíquica apta para um relacionamento sólido que deve ser, sobretudo, interiorizada pelos participantes e manifestada nos seus atos. E, segundo, este modelo de afetividade e regulação psíquica poderá ser uma fonte de inspiração e de ensinamentos para os portugueses melhorarem a sua condição emocional e relacional. Neste ponto, os especialistas relembram aos participantes, na cerimónia de compromisso do episódio 11, o facto de serem "um exemplo para os casais que estão em casa", graças ao crescimento pessoal e à maturidade psíquica que atingiram.

Não corresponde a este trabalho avaliar os efeitos pedagógicos do programa ou a sua eficácia. Tais operações significariam aceitar implicitamente a lógica da autodefinição do próprio programa, entendendo-o como um produto com uma finalidade essencialmente formativa. No entanto, como objeto cultural portador de diferentes repertórios acerca do amor, sim, pode ser examinado à luz da compatibilidade ou incompatibilidade desses repertórios. A verdade é que já foram assinaladas 
algumas tensões que, de algum modo, antecipam a argumentação que vai ser desenvolvida nesta secção. Essa argumentação centra-se na ideia de ambivalência. Defino a ambivalência, de acordo com Romero Moñivas (2016) e Martín Criado (2014), como a situação na qual os repertórios culturais prescrevem significados e guias de conduta contraditórios. No campo da cultura, e contrariamente ao defendido pelos modelos de inspiração parsoniana, a ambivalência é a regra. Isto implica que: (a) a cultura não é unitária nem necessariamente coerente; (b) existem ao nosso dispor repertórios culturais divergentes; (c) escolhemos segundo a situação e as restrições existentes; e (d) apesar da escolha, não somos nós, os indivíduos, os criadores do repertório. Esta é uma perspetiva da cultura afim à defendida, como vimos, por Ann Swidler através da sua metáfora da caixa de ferramentas.

Levando estas considerações ao terreno do amor, Swidler (2001:24-28) afirma que, na cultura ocidental, os requisitos institucionais do casamento exigem:

a) Exclusividade. Não é possível ser casado com duas pessoas ao mesmo tempo. Nesse sentido, o matrimónio exige dedicação exclusiva a um único indivíduo.

b) Decisão. Assume-se que deve ser escolhida a pessoa adequada, uma vez que essa resolução tem uma influência decisiva no futuro do indivíduo.

c) Durabilidade. Entende-se que o vínculo terá de ser mantido ao longo do tempo, isto é, não há de ser efémero.

d) Superação. Compreende-se que a união das duas pessoas permitirá ultrapassar conjuntamente os desafios e obstáculos que se apresentarão no seu percurso de vida.

Os repertórios culturais sobre o amor são elaborados à volta das linhas de ação estruturada pelas instituições, neste caso pelos requisitos do casamento como instituição. Sendo assim, o repertório cultural do amor como crescimento é usado para designar o trabalho, a análise, a negociação e a gestão emocional associados ao relacionamento afetivo. Exige a postergação da satisfação imediata em nome da plenitude no futuro e da responsabilidade pelo projeto de transformação pessoal. Trata-se de um repertório que os casais participantes mobilizam para organizar a sua ação quando se trata de satisfazer os requisitos institucionais da exclusividade, da durabilidade ou da superação. Um dos especialistas, Alexandre Machado, sintetiza de forma aproximada a complementaridade entre tais requisitos e o repertório do amor como crescimento: "Eu consigo compreender que as pessoas têm aquela atração física e que gostam daquele impulso inicial, mas uma relação, o bom da vida, e o que de facto tem valor é o que vem depois, é o amor, é a relação com longa duração com uma pessoa que é companheira, a nossa amiga." (Ep. 8) O discurso dos especialistas, que alimenta o repertório do amor como crescimento, enfatiza a responsabilidade individual pelo processo de transformação pessoal que há de sustentar o casamento, isto é, que deve garantir a exclusividade, a durabilidade e a superação. Mas, sob a perspetiva desse discurso, a decisão sobre a escolha sempre fica de fora da responsabilidade individual dos participantes. O conhecimento científico dos especialistas e as lacunas no desenvolvimento psicológico dos participantes, tal como provam as suas trajetórias erráticas no amor, justificaria que assim 
seja. Deste modo, o próprio discurso dos especialistas torna-se uma fonte contínua de ambivalência, que combina a responsabilização individual dos participantes com a sua desresponsabilização na decisão. Os casais, como vimos quando abordámos o tema da escolha, confirmam a incapacidade para adotar boas decisões. Ou como assinala Eliana: "não fiz boas escolhas, baseio as minhas relações em carências, coisas de curto prazo" (Ep. 4).

A ambivalência concretiza-se com clareza na figura de Ana, quando reflete sobre a sua relação com Hugo: "Eu queria muito acreditar na experiência apesar da minha intuição dizer o contrário... [Simula um diálogo consigo mesma] 'Não, [Ana] por alguma razão nos juntaram.' "' (Ep. 11) Aprofundando este ponto teremos uma ideia mais completa do sentido da ambivalência:

a) se com base no conhecimento dos especialistas é retirada ao indivíduo a possibilidade de escolher o seu par;

b) se essa escolha não pode ser interpretada de acordo com o léxico da intuição, do impulso e do sentimento, uma vez que foi adotada com base na determinação científica da compatibilidade psicológica;

c) se o indivíduo (neste caso, Ana) tem de interpretar uma situação de convivência difícil;

d) se esse indivíduo (de novo, Ana) sabe que os especialistas atribuíram um elevado grau de compatibilidade à sua relação com o parceiro selecionado;

e) se o repertório cultural que propõe o especialista para interpretar a situação de conflito está baseado na ideia de crescimento pessoal; e

f) se esse repertório continua a embater numa realidade de tensão na convivência;

o expetável é que o ceticismo ou a desconfiança sejam reações possíveis em Ana, uma vez que o léxico do amor como crescimento não confere sentido à realidade conflituosa vivenciada. Fica, pois, sem recursos culturais para compreender a situação e, por essa razão, recorre ao repertório do amor como sentimento mobilizando a ideia de "intuição".

À ambivalência cultural que gera a contraposição entre a responsabilização pela transformação individual e desresponsabilização pela escolha, une-se um outro elemento de tensão: a oposição entre a conveniência e o desejo. O repertório do amor como crescimento fornece recursos para entender como deve prosperar e ser mantido um casamento a partir de uma disposição psicológica individual apropriada. Dito de um outro modo, explica o que convém ao casamento e ao casal. Isabel, por exemplo, diz que, juntamente com o seu par, Claúdio, tem feito todo o trabalho de crescimento individual. E acrescenta: "Agora temos de sentir." (Ep. 10) O repertório cultural do amor como sentimento volta a ser convocado na medida em que se torna relevante para outorgar sentido a uma situação para a qual o amor como crescimento não fornece respostas adequadas. Apesar de o processo de transformação pessoal avançar, sem a matéria que traz consigo o sentimento o casamento fica comprometido. Como afirma Daniela, "estamos apaixonados pela ideia do amor" (Ep. 6), isto é, o repertório cultural do amor como sentimento é apelativo para a experiência pessoal e aproxima-se de ideias como a excitação, a aventura, o 
magnetismo, a magia e o entusiasmo (Illouz, 2009: 231). Crescer psicologicamente pode ser o mais conveniente, mas é insuficiente para dar conta da situação do casamento, inviável sem o recurso ao repertório do amor como sentimento.

\section{Conclusão}

Até aqui, analisámos os repertórios culturais sobre o amor em "Casados à Primeira Vista". Dada a lógica do programa, o repertório central é o do amor como crescimento, materializado, principalmente, no discurso dos especialistas. Este repertório refere o tipo de preparação psicológica e de desenvolvimento pessoal que predispõe para um relacionamento frutuoso. Assume que o fracasso nos relacionamentos está associado a algum tipo de lacuna psíquica, à ausência de uma disposição mental apropriada. Contudo, este repertório não é suficiente para conferir sentido a todas os requisitos institucionais que impõe o matrimónio. Daí que um segundo repertório, o do amor como sentimento, surja como recurso interpretativo gerando tensões com o primeiro. Desse modo, assiste-se à produção de ambivalência cultural: os requisitos institucionais do casamento exigem a mobilização de dois repertórios não necessariamente compatíveis.

Em CPV, o amor é explicado, essencialmente, a partir de uma perspetiva individualizada, onde os atributos psicológicos são a variável definitiva. Isto implica que as condições sócio-estruturais do amor sejam obscurecidas. Tais condições, em $\mathrm{CPV}$, parecem não existir e, como tal, tudo quanto acontece é apresentado como sendo relativo ao foro da psique. Ou, por outras palavras, se o amor não se concretiza e o casamento decai, a explicação reside na incorreta disposição psicológica do indivíduo, um indivíduo que psiquicamente não cresceu na medida necessária.

Mas, como aponta Illouz (2012: 60-108), as condições sócio-estruturais são responsáveis pelas causas das situações que devem ser confrontadas com os repertórios culturais que os indivíduos têm ao seu dispor. Não podemos reproduzir aqui uma explicação pormenorizada destas condições que, genericamente, estão relacionadas com:

a) os desequilíbrios económicos entre homens e mulheres e a desigual possibilidade de conciliação entre a vida pessoal e a profissional;

b) as exigências estéticas que pesam sobre o corpo da mulher, culturalmente percebido como um elemento mais firmemente condicionado pelo tempo;

c) a sexualidade masculina baseada em contactos crescentes e sucessivos como estatuto compensatório face à erosão da masculinidade tradicional propiciada pela redução da desigualdade entre homens e mulheres, um fenómeno que na nossa cultura é conceptualizado como medo ou aversão ao compromisso.

Essas condições são timidamente referidas por Daniela (Ep. 1 e 2) quando fala, por exemplo, da fragmentação dos espaços de sociabilidade e de encontro para pessoas com a sua idade e caraterísticas, substituídos pela sobreabundância e pelo caráter efémero e superficial dos contactos nas plataformas virtuais e nas redes sociais. 
Também menciona a escassez de tempo nas mulheres separadas ou divorciadas, que compatibilizam a vertente profissional com o cuidado e a educação dos filhos em regimes pouco equitativos com os pais. Por último, adverte que os filhos são, em ocasiões, um critério excludente para muitos homens, que procuram mulheres que não sejam mães ou que não tenham crianças ao seu cargo. A individualização do amor vinculada à linguagem do crescimento sugere uma resolução individual, mediante a adequada disposição psicológica, das dificuldades que geram essas condições sociais. $\mathrm{Ou}$, dito de um outro modo, tais condições são traduzidas em estados psíquicos problemáticos que os indivíduos hão de confrontar com a ajuda e as ferramentas dos especialistas. Como assinala Swidler, a origem e produção dos repertórios culturais é social, o que contrasta com o peso definitivo que o repertório central de CAP, o do amor como crescimento, outorga ao indivíduo. De algum modo, é assim, através deste repertório veiculado na televisão, que a sociedade acaba por desaparecer do nosso imaginário cultural sobre o amor.

\section{Referências bibliográficas}

Bardin, Laurence (2011), Análise de Conteúdo, São Paulo, Edições 70 / Almedina Brasil. Bauman, Zygmunt (2006), Amor Líquido. Sobre a Fragilidade dos Laços Humanos, Lisboa, Relógio d'Água.

Beck, Ulrich, e Elisabeth Beck-Gernsheim (2001), El Normal Caos del Amor. Las Nuevas Formas de la Relación Amorosa, Barcelona, Paidós.

Bellah, Robert, Richard Madsen, William M. Sullivan, Ann Swidler, e Steven M. Tipton (1985), Habits of the Heart. Individualism and Commitment in American Life, Berkeley, University of California Press.

Biressi, Anita, e Heather Nunn (2005), Reality TV. Realism and Revelation, Londres, Wallflower Press.

Casetti, Francesco, e Federico Di Chio (1999), Análisis de la Televisión. Instrumentos, Métodos y Prácticas de Investigación, Barcelona, Paidós.

Costa Sánchez, Carmen (2010), “Coaching shows: análisis de un nuevo género televisivo", Área Abierta, 27, pp. 1-15.

Escoffery, David S. (org.) (2006), How Real is Reality Television. Essays on Representation and Truth, Jefferson, NC, McFarland \& Company.

Felmlee, Diane H., e Susan Sprecher (2006), “Love”, em Jan E. Stets e Jonathan H. Turner, Handbook of the Sociology of Emotions, Nova Iorque, Springer, pp. 389-409.

García Andrade, Adriana (2015), "El amor como problema sociológico", Acta Sociológica, 66, pp. 35-60.

García Martínez, Alberto Nahum (2009), “La hibridación de lo real: simulacro y performatividad en la era de la postelerrealidad", Anàlisi, 38, pp. 237-251.

Giddens, Anthony (1997), Modernidad e Identidad del Yo, Barcelona, Península.

Gordillo, Inmaculada, e María del Mar Ramírez Alvarado (2009), “Fórmulas y formatos de la telerrealidad: taxonomía del hipergénero docudramático", em Bienvenido León (coord.), Telerrealidad. El Mundo Tras el Cristal, Sevilha, Comunicación Social Ediciones y Publicaciones, pp. 22-35. 
Hall, Alice E. (2009), "Perceptions of media realism and reality TV", em Robin L. Nabi e Mary Beth Oliver (orgs.), The Sage Handbook of Media Processes and Effects, Thousand Oaks, CA, Sage, pp. 423-438.

Hill, Annette (2014), Reality TV. Audiences and Popular Factual Television, Londres e Nova Iorque, Routledge.

Hochschild, Arlie Russell (2003), The Commercialization of Intimate Life. Notes from Home and Work, Berkeley, University of California Press.

Illouz, Eva (2003), Oprah Winfrey and The Glamour of Misery. An Essay on Popular Culture, Nova Iorque, Columbia University Press.

Illouz, Eva (2008), Saving the Modern Soul. Therapy, Emotions and the Culture of Self-Help, Berkeley, University of California Press.

Illouz, Eva (2009), El Consumo de la Utopia Romântica. El Amor y las Contradicciones Culturales del Capitalismo, Buenos Aires / Madrid, Katz Editores.

Illouz, Eva (2012), Why Love Hurts. A Sociological Explanation, Cambridge / Malden, MA, Polity Press.

Jones, Janet Megan (2003), “Show your real face: a fan study of the UK Big Brother transmissions $(2000,2001,2002)$ investigating the boundaries betwenn notions of consumers and producers of factual television", New Media \& Society, 5 (3), pp. 400-421.

Kavka, Misha (2005), “Love'n the real, or how I learned to love reality TV”, em Geoff King (org.), The Spectacle of the Real. From Hollywood to Reality TV and Beyond, Bristol / Portland, Intellect, pp. 93-103.

Kavka, Misha (2012), Reality TV, Edimburgo, Edinburgh University Press.

Martín Criado, Enrique (2014), "Mentiras, inconsistências y ambivalências: teoría de la acción y análisis del discurso", Revista Internacional de Sociología, 72 (1), pp. 115-138.

Montemurro, Beth (2008), “Toward a sociology of reality television”, Sociology Compass, 2 (1), pp. 84-106.

Romero Moñivas, Jesús (2016), “Una aproximación teórica a la ambivalência humana y sus implicaciones para la sociologia", Empiria - Revista de Metodología de Ciencias Sociales, 33, pp. 37-64.

Schudson, Michael (1989), "How culture works: perspectives from media studies on the efficacy of symbols", Theory and Society, 18, pp. 153-180.

Swidler, Ann (1986), "Culture in action: symbols and strategies", American Sociological Review, 51, pp. 273-286.

Swidler, Ann (2001), Talk of Love. How Culture Matters, Chicago / Londres, The Chicago University Press.

Fernando Ampudia de Haro. Professor na Universidade Europeia, Lisboa, Portugal. E-mail: fernando.ampudia@universidadeeuropeia.pt ORCID: 0000-0001-6470-1912

Receção: 18 de janeiro de 2021 Aprovação: 13 de julho de 2021 
